\title{
Evidence-based guideline summary: Evaluation, diagnosis, and management of congenital muscular dystrophy
}

Report of the Guideline Development Subcommittee of the American Academy of Neurology and the Practice Issues Review Panel of the American Association of Neuromuscular \& Electrodiagnostic Medicine

\section{미숫}

Peter B. Kang, MD

Leslie Morrison, MD

Susan T. Iannaccone, MD

Robert J. Graham, MD

Carsten G. Bönnemann,

MD

Anne Rutkowski, MD

Joseph Hornyak, MD,

$\mathrm{PhD}$

Ching H. Wang, MD,

$\mathrm{PhD}$

Kathryn North, MD,

FRACP

Maryam Oskoui, MD

Thomas S.D. Getchius

Julie A. Cox, MFA

Erin E. Hagen

Gary Gronseth, MD

Robert C. Griggs, MD

Correspondence to

American Academy of Neurology: guidelines@aan.com

Supplemental data at Neurology.org

\section{ABSTRACT}

Objective: To delineate optimal diagnostic and therapeutic approaches to congenital muscular dystrophy (CMD) through a systematic review and analysis of the currently available literature.

Methods: Relevant, peer-reviewed research articles were identified using a literature search of the MEDLINE, EMBASE, and Scopus databases. Diagnostic and therapeutic data from these articles were extracted and analyzed in accordance with the American Academy of Neurology classification of evidence schemes for diagnostic, prognostic, and therapeutic studies. Recommendations were linked to the strength of the evidence, other related literature, and general principles of care.

Results: The geographic and ethnic backgrounds, clinical features, brain imaging studies, muscle imaging studies, and muscle biopsies of children with suspected CMD help predict subtype-specific diagnoses. Genetic testing can confirm some subtype-specific diagnoses, but not all causative genes for CMD have been described. Seizures and respiratory complications occur in specific subtypes. There is insufficient evidence to determine the efficacy of various treatment interventions to optimize respiratory, orthopedic, and nutritional outcomes, and more data are needed regarding complications.

Recommendations: Multidisciplinary care by experienced teams is important for diagnosing and promoting the health of children with CMD. Accurate assessment of clinical presentations and genetic data will help in identifying the correct subtype-specific diagnosis in many cases. Multiorgan system complications occur frequently; surveillance and prompt interventions are likely to be beneficial for affected children. More research is needed to fill gaps in knowledge regarding this category of muscular dystrophies. Neurology ${ }^{\circledR} 2015 ; 84: 1369-1378$

\section{GLOSSARY}

AAN = American Academy of Neurology; AANEM = American Association of Neuromuscular \& Electrodiagnostic Medicine; B3GALNT2 $=\beta-1,3-N$-acetylgalactosaminyltransferase 2; B3GNT1 $=\beta-1,3-N$-acetylglucosaminyltransferase 1; CK $=$ creatine kinase; CMD = congenital muscular dystrophy; COL6A1 = collagen 6 $\alpha 1$; COL6A2 = collagen 6 $\alpha 2$; COL6A3 = collagen 6 $\alpha 3$; DAG1 $=\alpha$-dystroglycan; FKTN = fukutin; GMPPB = GDP-mannose pyrophosphorylase B; LAMA2 = laminin $\alpha 2 ;$ LMNA = lamin $\mathrm{A} / \mathrm{C} ; \mathbf{M D}=$ muscular dystrophy; $\mathbf{M D C}=$ merosin-deficient congenital muscular dystrophy; $\mathbf{S E P N 1}=$ selenoprotein $1 ; \mathbf{S G K 1 9 6}=$ protein-O-mannose kinase; TMEM5 = TMEM5.

This document summarizes extensive information provided in the complete guideline, available as a data supplement on the Neurology ${ }^{\circledR}$ Web site at Neurology.org. Tables e- 1 and e-2 and appendices e-1 through e-9, cited in the full guideline (data supplement), as well as references e1-e95, cited in this summary, are available at Neurology.org. The systematic review and practice recommendations were developed according to the processes described in the 2004 and 2011 American Academy of

From the Division of Pediatric Neurology (P.B.K.), University of Florida College of Medicine, Gainesville; Department of Neurology (P.B.K.), Boston Children's Hospital and Harvard Medical School, Boston, MA; Department of Neurology (L.M.), University of New Mexico, Albuquerque; Departments of Pediatrics and Neurology \& Neurotherapeutics (S.T.I.), University of Texas Southwestern Medical Center, and Children's Medical Center, Dallas; Division of Critical Care Medicine (R.J.G.), Boston Children's Hospital, and Department of Anaesthesia, Harvard Medical School, Boston; Neuromuscular and Neurogenetic Disorders of Childhood Section (C.G.B.), Neurogenetics Branch, National Institute of Neurological Disorders and Stroke, National Institutes of Health, Bethesda, MD; Cure Congenital Muscular Dystrophy (Cure CMD) (A.R.), Olathe, KS; Department of Emergency Medicine (A.R.), Kaiser Permanente South Bay Medical Center, Harbor City, CA; Department of Physical Medicine \& Rehabilitation (J.H.), University of Michigan, Ann Arbor; Departments of Neurology and Pediatrics (C.H.W.), School of Medicine, Stanford University, CA; Department of Neurology (C.H.W.), Driscoll Children's Hospital, Corpus Christi, TX; Murdoch Childrens Research Institute (K.N.), The Royal Children's Hospital, and University of Melbourne, Australia; Neurology \& Neurosurgery (M.O.), McGill University, Montréal, Canada; Center for Health Policy (T.S.D.G., J.A.C., E.E.H.), American Academy of Neurology, Minneapolis, MN; Department of Neurology (G.G.), University of Kansas School of Medicine, Kansas City; and Department of Neurology (R.C.G.), University of Rochester Medical Center, NY.

Approved by the AAN Guideline Development Subcommittee on July 13, 2013; by the AAN Practice Committee on May 26, 2014; by the AANEM Board of Directors on December 24, 2014; and by the AANI Board of Directors on December 17, 2014.

This guideline was endorsed by the American Academy of Pediatrics on September 12, 2014; by the American Occupational Therapy Association on August 1, 2014; by the Child Neurology Society on July 11, 2014; and by the National Association of Neonatal Nurses on April 5, 2014. Go to Neurology.org for full disclosures. Funding information and disclosures deemed relevant by the authors, if any, are provided at the end of the article. 
Neurology guideline development process manuals. ${ }^{1,2}$ The principal audience for this guideline is clinicians caring for patients with congenital muscular dystrophies (CMDs).

The CMDs are a group of rare muscular dystrophies (MDs) that have traditionally been defined as having symptom onset at birth. CMDs are distinct from congenital myopathies, which are characterized by different pathologic features and genetic etiologies. ${ }^{3}$ Epidemiologic data are sparse. The prevalence has been reported to be $6.8 \times 10^{-6}$ in 1993 in northeast Italy ${ }^{4}$ and $2.5 \times 10^{-5}$ among children aged 16 years and younger in western Sweden, ${ }^{5}$ data which suggest that at least in European populations, the prevalence is likely to be in the range of 1 in 100,000 people.

Due in part to recent genetic advances, a broader phenotypic spectrum is now recognized for $\mathrm{CMD},{ }^{6}$ and the exact age at onset may be difficult to define in some cases, especially for the milder variants. Thus, MDs with onset in the first 2 years of life, especially during infancy (the first year of life), are now commonly considered to be CMDs. One lingering nosological question is whether a later-onset disease that is allelic to a CMD should be classified as a CMD or a different disease.

Three major categories of CMDs are commonly recognized, each of which has distinct, welldescribed phenotypic features: (1) collagenopathies (also known as collagen VI-related myopathies), including Ullrich CMD and Bethlem myopathy ${ }^{7,8}$; (2) merosinopathies (also known as merosindeficient CMDs [MDCs], laminin $\alpha 2$ [LAMA2]related CMDs, and MDC1A); and (3) dystroglycanopathies (also known as $\alpha$-dystroglycan-related MDs), including Fukuyama CMD, ${ }^{9}$ muscle-eyebrain disease, and Walker-Warburg syndrome.

Other rare CMDs do not fit into any of the classic categories. Tables 1 and 2 list these CMDs with their associated genes and clinical phenotypes. More recently, several other genes have been associated with CMDs, including GTDC2, ${ }^{10}$ TMEM $5,{ }^{11}$ B3GALNT2, ${ }^{12}$ SGK196, ${ }^{13}$ B3GNT1, ${ }^{14}$ GMPPB, ${ }^{15}$ and $D A G 1{ }^{16}$

Whereas the genetic, pathophysiologic, and pathologic features of the CMDs have become better understood in recent decades, optimal diagnostic and therapeutic approaches remain unclear. However, a recently published set of algorithms will help with the diagnostic process for patients with suspected CMD. ${ }^{6}$

ANALYSIS OF EVIDENCE To inform recommendations for the diagnosis, management, and treatment of CMD, the authors performed systematic reviews to answer the questions presented below.
For children with suspected CMD, how accurately do the (a) geographic location and ethnicity, (b) clinical features, (c) brain imaging findings, (d) muscle imaging findings, and (e) muscle biopsy findings predict the subtype-specific diagnosis? Geographic location and ethnicity. One Class I study, ${ }^{17} 4$ Class II studies, ${ }^{18-21}$ and 1 Class III study ${ }^{22}$ demonstrated that in children with suspected CMD, founder mutations lead to clusters of certain mutations in the Japanese (Fukuyama CMD), Korean (Fukuyama CMD), Ashkenazi Jewish (Walker-Warburg syndrome), and Turkish (A200P haplotype in the POMT1 gene) populations. Other founder mutations likely exist. Thus, the geographic and ethnic background of children with suspected CMD may help predict the specific subtype when information is available for the population of interest.

Clinical features. Progressive skeletal muscle weakness and hypotonia are the cardinal clinical manifestations of the CMDs. Serum creatine kinase (CK) levels are typically but not invariably elevated. One Class II study and 1 Class III study demonstrated that distal joint hyperlaxity, congenital hypotonia, and joint contractures are characteristic clinical features associated with collagenopathy. ${ }^{23,24}$ One Class II study showed that the classic clinical findings of congenital weakness, elevated serum CK levels, and white matter signal abnormalities on brain MRI predict the merosinopathy subtype. ${ }^{25}$ One Class II study ${ }^{26}$ and 3 Class III studies ${ }^{27-29}$ provided evidence that classic patterns of muscle weakness, structural eye abnormalities, and cortical brain abnormalities (this last often associated with migrational defects) characteristic of dystroglycanopathies are often predictive of mutations in known genes for those syndromes. A Class III study found that L-CMD ( $L M N A$-associated CMD) is strongly associated with neck extensor weakness. ${ }^{30}$ Thus, in children with suspected CMD, clinical features may predict subtype-specific diagnoses and may in some cases predict the causative genes.

Brain imaging findings. Two Class II studies ${ }^{31,32}$ and 1 Class III study ${ }^{33}$ demonstrated that abnormal findings on brain imaging studies can predict the subtype-specific diagnosis in some cases, especially in merosinopathy (white matter abnormalities) and some dystroglycanopathies (polymicrogyria, white matter lesions, pontine hypoplasia, and subcortical cerebellar cysts).

Muscle imaging. Three Class I articles ${ }^{34-36}$ and 1 Class II article ${ }^{37}$ provided evidence that skeletal muscle imaging in children with suspected CMD using MRI, ultrasound, and CT often demonstrates signal abnormalities that suggest subtype-specific diagnoses. This has been most extensively documented in CMD subtypes associated with rigidity of the spine, such as collagenopathies and SEPN1related myopathy. 
Table 1 The congenital muscular dystrophies

\begin{tabular}{|c|c|c|}
\hline Disease & Gene symbol & Protein \\
\hline \multicolumn{3}{|c|}{ Collagenopathies: autosomal recessive and autosomal dominant } \\
\hline \multirow[t]{3}{*}{ Ullrich congenital MD } & COL6A1 $1^{\mathrm{e} 15, \mathrm{e} 79}$ & Collagen $6 \alpha 1$ \\
\hline & COL6A2 $23, e 12$ & Collagen $6 \alpha 2$ \\
\hline & COL6A3 $3^{\mathrm{e} 0}$ & Collagen $6 \alpha 3$ \\
\hline \multirow[t]{3}{*}{ Bethlem myopathy } & COL6A1 ${ }^{\mathrm{e} 81}$ & Collagen $6 \alpha 1$ \\
\hline & COL6A2 ${ }^{\mathrm{e} 81}$ & Collagen $6 \propto 2$ \\
\hline & COL6A3 ${ }^{\mathrm{e} 82}$ & Collagen $6 \alpha 3$ \\
\hline \multicolumn{3}{|l|}{ Merosinopathy: autosomal recessive } \\
\hline Merosin-deficient CMD & LAMA2 20 & Merosin \\
\hline \multicolumn{3}{|c|}{ Dystroglycanopathies: autosomal recessive } \\
\hline Fukuyama CMD & FKTN $^{\mathrm{e} 29}$ & Fukutin \\
\hline \multirow[t]{3}{*}{ Muscle-eye-brain disease } & POMGnT1 27,eз2,e83 & POMGnT1 \\
\hline & FKRP ${ }^{\mathrm{e} 84}$ & Fukutin-related protein \\
\hline & РОMT2 $26, e 85$ & РОМТ2 \\
\hline \multirow[t]{10}{*}{ Walker-Warburg syndrome } & POMT1 ${ }^{\mathrm{e} 34, \mathrm{e} 86}$ & РОMT1 \\
\hline & РOMT2 ${ }^{\mathrm{e} 7}$ & РОМТ2 \\
\hline & POMGnT1 ${ }^{e 88}$ & POMGnT1 \\
\hline & FKTN $\mathrm{e}^{\mathrm{e} 4}$ & Fukutin \\
\hline & FKRPe84 & Fukutin-related protein \\
\hline & LARGE ${ }^{\mathrm{e} 26}$ & LARGE \\
\hline & ISPD 11,e89-e91 & ISPD \\
\hline & $\begin{array}{l}\text { POMGnT2/ } \\
\text { GTDC2 }^{10}\end{array}$ & POMGnT2 \\
\hline & B3GNT1 ${ }^{14}$ & $\begin{array}{l}\beta-1,3-N \text {-acetylglucosaminyltransferase } \\
1\end{array}$ \\
\hline & SGK196 13 & Protein-O-mannose kinase \\
\hline Primary $\alpha$-dystroglycanopathy & $D A G 1^{16}$ & $\alpha$-Dystroglycan \\
\hline MDDGA10 & TMEM5 $^{11}$ & TMEM5 \\
\hline MDDGA11 & B3GALNT2 ${ }^{12}$ & $\begin{array}{l}\beta-1,3-\mathrm{N}- \\
\text { acetylgalactosaminyltransferase } 2\end{array}$ \\
\hline MDDGA14 & GMPPB $^{15}$ & GDP-mannose pyrophosphorylase B \\
\hline \multicolumn{3}{|l|}{ Unclassified CMDs } \\
\hline \multirow[t]{2}{*}{ Rigid spine syndrome } & SEPN1 ${ }^{\text {e92 }}$ & Selenoprotein N, 1 \\
\hline & FHL1 $1^{\mathrm{e} 93}$ & Four-and-a-half LIM domain 1 \\
\hline Multiminicore disease & SEPN1 ${ }^{\mathrm{e} 94}$ & Selenoprotein N, 1 \\
\hline L-CMD & LMNA $A^{e 95}$ & Lamin $A / C$ \\
\hline
\end{tabular}

Abbreviations: $C M D$ = congenital muscular dystrophy; $L-C M D=L M N A$-associated CMD; MD = muscular dystrophy. See www.musclegenetable.fr for current information.

Muscle biopsy findings. CMDs share characteristic muscle biopsy findings with other MDs, including necrosis, regenerating fibers, fiber size variability, and increased perimysial and endomysial connective tissue. Three Class II $^{20,21,38}$ and 3 Class III ${ }^{39,40, e 1}$ articles demonstrated that immunohistochemistry can identify the presence of a merosinopathy (LAMA2) or dystroglycanopathy. Evidence is insufficient to determine the capability of muscle biopsies to identify collagenopathies.
How often does genetic testing confirm a diagnosis of CMD? CMDs are often autosomal recessive, but some cases have been found to follow autosomal dominant patterns, by direct inheritance, spontaneous mutations, or mosaicism. The genetic origins of many cases of CMD have been discovered. ${ }^{22}$ However, many affected individuals remain without a genetic diagnosis, an indicator that novel disease genes have yet to be identified. Clinical genetic testing is available for virtually all genes known to be associated with CMD. 
Table 2 Clinical features of the congenital muscular dystrophies

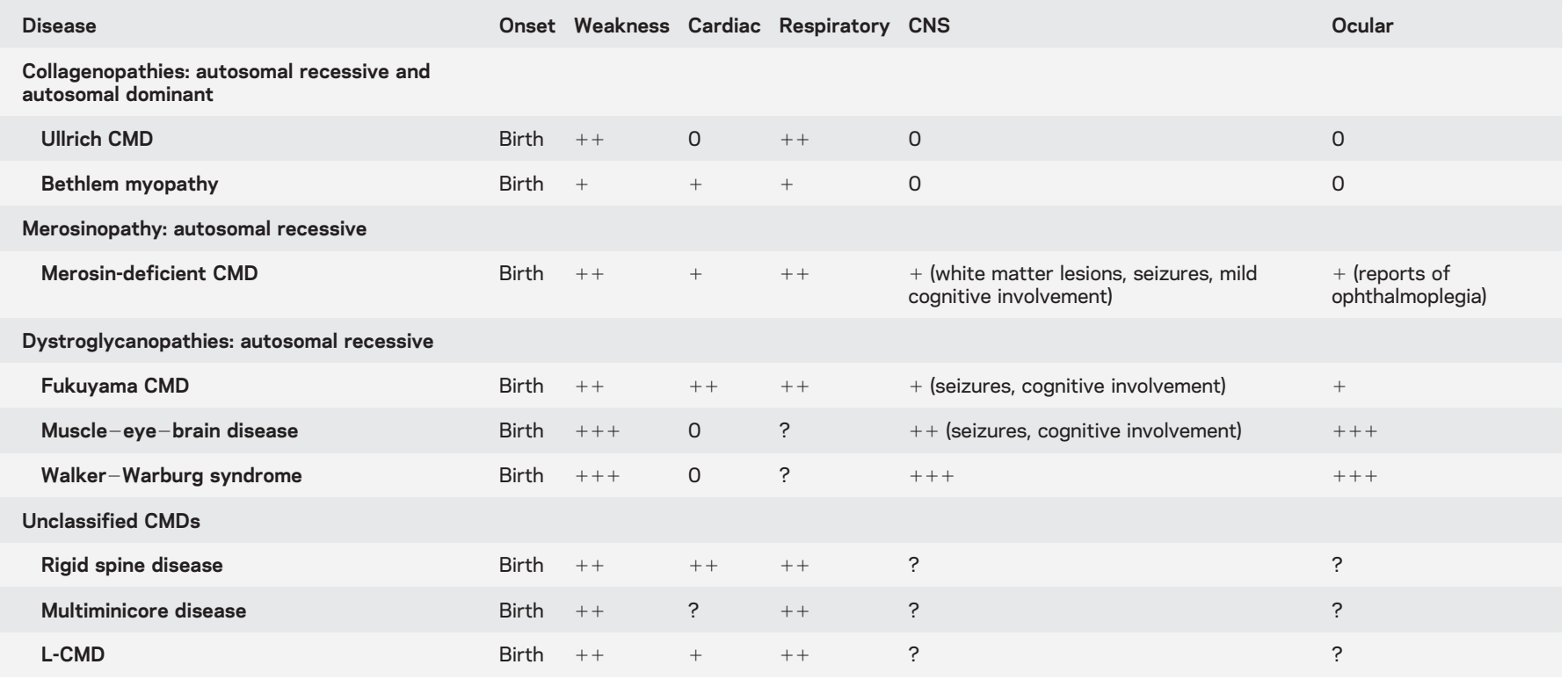

Abbreviations: $\mathrm{CMD}=$ congenital muscular dystrophy; L-CMD = LMNA-associated CMD.

$0=$ none $;+=$ mild $;++=$ moderate $;+++=$ severe .

Our systematic review identified 2 Class III studies $^{\mathrm{e} 3,{ }^{24}}$ that found that the mutation detection rate for CMDs in general ranges from $20 \%$ to $46 \%$.

In children with collagenopathy (Ullrich CMD or Bethlem myopathy), 1 Class II study, ${ }^{\mathrm{e}} 5$ large Class III studies, ${ }^{\text {e6-e10 }}$ and 7 small Class III studies ${ }^{\mathrm{e} 1-\mathrm{el} 17}$ indicate that COL6A1, COLGA2, and COLGA3 genetic testing possibly has a high likelihood of detecting causative mutations.

Two large Class III studies ${ }^{\mathrm{e} 18, \mathrm{e} 19}$ provided evidence that in children with complete merosin deficiency on muscle biopsy, LAMA2 genetic testing has a high likelihood of detecting causative mutations. Two smaller Class III studies ${ }^{\mathrm{e} 20, \mathrm{e} 21}$ demonstrated that in children with partial merosin deficiency, LAMA2 mutation detection is less consistent. Evidence provided by 1 Class II diagnostic/Class III screening study $^{\mathrm{e} 22}$ and 1 Class III study ${ }^{\mathrm{e} 23}$ indicates that prenatal genetic testing is highly accurate.

Seven Class IIII $22,26, \mathrm{e} 24-\mathrm{e} 28$ studies demonstrated that genetic testing can detect causative mutations in 30\% to $66 \%$ of children with dystroglycanopathy. In Fukuyama CMD, FKTN mutations are detected in as many as $100 \%$ of patients (1 Class I diagnostic/Class III screening study ${ }^{17}$ and 3 Class III screening studie $\left.^{\mathrm{e}^{29-e 31}}\right)$. In muscle-eye-brain disease, POMGnT1 mutations may be detected in $100 \%$ of patients (2 Class III studies). ${ }^{27,632}$ In Walker-Warburg syndrome, only $40 \%$ of patients have mutations in the known genes (1 large Class III study ${ }^{333}$ and 2 smaller Class III studies ${ }^{\mathrm{e} 34,235}$ ).

How often do patients with CMD experience cognitive, respiratory, or cardiac complications? Numerous reports highlight a wide spectrum of complications in children and young adults with CMD.

Functional CNS complications. One Class II study found that $58 \%$ of patients with CMD had cognitive impairment. ${ }^{\mathrm{e} 6} \mathrm{~A}$ Class III article reported a high incidence of seizures in a cohort of Japanese children with Fukuyama CMD. ${ }^{\text {e31 }}$ Another Class III article reported that 2 girls with dystroglycanopathy had epilepsy associated with unusual EEG findings. ${ }^{\mathrm{e} 7}$

Respiratory complications. A Class III study found an overall respiratory complication rate of $12 \%$ in CMD. ${ }^{38}$ Another Class III study found that forced vital capacity was $<80 \%$ predicted in all patients with Ullrich CMD by age 6 years. ${ }^{e 39}$ One Class III study examined the use of polysomnography in 2 patients with CMD and 2 patients with rigid spine syndrome and found that all subjects experienced nocturnal hypoventilation and hypoxemia. ${ }^{\text {e40 }}$

Cardiac complications. One Class III study noted an overall cardiac complication rate of $6 \%$ in CMD. ${ }^{\text {e38 }}$ Three Class III studies examining echocardiographic measurements estimated that $8 \%$ to $30 \%$ of patients with merosin-positive CMD had depressed cardiac function..$^{\text {e41-e43 }}$

Feeding difficulties. In a Class III study, the families of all 14 children with merosinopathy reported that their children had feeding difficulties. ${ }^{444}$

Are there effective treatments for complications of CMD, including scoliosis and nutritional deficiencies? Our systematic review identified 1 Class III study of spinal fusion that demonstrated correction and prevention of progression of scoliosis and pelvic obliquity over 2 years, resulting in improved or stable balance and 
sitting posture. The impact on respiratory status and other complications was unclear. ${ }^{\text {e45 }}$

PRACTICE RECOMMENDATIONS Given the lack of literature directly relevant to CMDs for some of the clinical questions, some of the following recommendations are based in part on evidence from other neuromuscular disorders of childhood.

General recommendations. Patients with CMD may develop various combinations of cardiovascular, gastrointestinal/nutritional, neurologic, ophthalmologic, orthopedic, and pulmonary manifestations. Multidisciplinary teams are recommended in the care of patients with complex neuromuscular conditions such as amyotrophic lateral sclerosis. ${ }^{\text {e46 }}$ Neuromuscular specialists, particularly child neurologists and physiatrists with subspecialty training, are key members of such teams, as are physicians from other specialties (e.g., cardiology, gastroenterology, neurology, ophthalmology, orthopedic surgery, pulmonology) and allied health professionals with relevant expertise (e.g., dieticians, genetic counselors, nurses, nurse practitioners, occupational therapists, physical therapists, and speech-language pathologists).

\section{Recommendations.}

1. Physicians caring for children with CMD should consult a pediatric neuromuscular specialist for diagnosis and management (Level B).

2. Pediatric neuromuscular specialists should coordinate the multidisciplinary care of patients with CMD when such resources are accessible to interested families (Level B).

3. When genetic counselors are available to help families understand genetic test results and make family-planning decisions, physicians caring for patients with CMD might help families access such resources (Level B).

Use of clinical features, MRI, and muscle biopsy in diagnosis. Patients with some of the classic CMD subtypes, including collagenopathies and dystroglycanopathies, have distinct phenotypic features that may help focus the diagnostic process.

\section{Recommendation.}

1. Physicians should use relevant clinical features such as ethnicity and geographic location, patterns of weakness and contractures, the presence or absence of CNS involvement, the timing and severity of other organ involvement, and serum CK levels to guide diagnosis in collagenopathies and in dystroglycanopathies (Level B).

Interpretation of muscle biopsy findings, especially in children, is heavily dependent on technique and the experience of the pathologist or neuromuscular specialist who interprets the studies. Proper interpretation of these studies requires knowledge of the clinical context as well as availability of advanced testing capabilities. The knowledge obtained from a muscle biopsy may help families and providers better understand the disease process affecting specific patients.

\section{Recommendations.}

1. Physicians might order muscle biopsies that include immunohistochemical staining for relevant proteins in CMD cases for which the subtype-specific diagnosis is not apparent after initial diagnostic studies, if the risk associated with general anesthesia is determined to be acceptable (Level C).

2. When muscle biopsies are indicated in cases of suspected CMD, they should be performed and interpreted at centers experienced in this test modality. In some cases, optimal diagnostic information may be derived when the biopsy is performed at one center and interpreted at another (Level B).

Typical brain MRI findings of white matter abnormalities in merosinopathies can be found consistently above the age of 6 months, ${ }^{\text {e24,e47 }}$ and the structural brain abnormalities that often accompany the dystroglycanopathies are well documented.

Muscle ultrasound and MRI studies can help distinguish neurogenic from myopathic disorders ${ }^{34}$ and show pathognomonic patterns for specific CMD subtypes. ${ }^{35}$ Muscle MRI studies likewise can help identify CMD subtypes, including collagenopathies and SEPN1-related myopathies. ${ }^{36}$

\section{Recommendations.}

1. Physicians should order brain MRI scans to assist with the diagnosis of patients with clinically suspected CMD subtypes such as merosinopathies and dystroglycanopathies, if the potential risk associated with any sedation is determined to be acceptable and if a radiologist or other physician with the appropriate expertise is available to interpret the findings (Level B).

2. Physicians might order muscle imaging studies of the lower extremities for individuals with suspected CMD subtypes such as collagenopathies (ultrasound or MRI) and SEPN1-related myopathy (MRI), if the risk associated with any sedation needed is determined to be acceptable and if a radiologist or other physician with the appropriate expertise is available to interpret the findings (Level C).

Genetic diagnosis. Targeted genetic testing often identifies causative mutations in the classic CMD subtypes. However, the cost of traditional Sanger sequencing for some of the larger causative genes presents an obstacle to universal application of such 
sequencing, even though the testing is readily available. ${ }^{\text {e48 }}$ Genetic diagnoses are beneficial to the patient, as they often enable physicians to provide more accurate prognoses and facilitate genetic counseling and family-planning discussions, and may enable patients to become more aware of future clinical trials for which they may be eligible.

\section{Recommendation.}

1. When available and feasible, physicians might order targeted genetic testing for specific CMD subtypes that have well-characterized molecular causes (Level C).

Our systematic review indicates that many patients with CMD do not have mutations in one of the currently known genes. The cost of next-generation sequencing (whole-exome and whole-genome sequencing) is dropping rapidly, to the point where these technologies are now readily available to many researchers who seek novel causative disease genes. ${ }^{\text {eq }} 9$

\section{Recommendation.}

1. In individuals with CMD who either do not have a mutation identified in one of the commonly associated genes or have a phenotype whose genetic origins have not been well characterized, physicians might order whole-exome or wholegenome sequencing when those technologies become more accessible and affordable for routine clinical use (Level C).

Complications and treatment. Patients with CMD experience a broad spectrum of respiratory, musculoskeletal, cognitive, and cardiac complications with variable tempo between individuals. Providers may, in appropriate circumstances, extrapolate from earlyonset neuromuscular and neuromotor diseases for which consensus guidelines have been developed on the basis of both established principles of care and limited outcomes and intervention trials. ${ }^{\text {e50-e54 }}$ There are currently no curative CMD subtype-specific interventions. Thus, all complication screening and interventions are intended to promote growth and potential development, mitigate cumulative morbidities, optimize function, and limit mortality while maximizing quality of life. ${ }^{\mathrm{e} 55}$

\section{Recommendation.}

1. At the time of diagnosis, the physician should advise families regarding areas of uncertainty such as clinical outcomes and the value of interventions as they pertain to both longevity and quality of life. Physicians should explain the multisystem implications of neuromuscular insufficiency and guide families as they make decisions regarding the monitoring for and treatment of CMD complications (Level B).
Respiratory complications. Patients with respiratory failure from neuromuscular-related weakness may experience conspicuous respiratory symptoms but often do not have symptoms such as dyspnea that precede the onset of respiratory failure. ${ }^{556}$ Noninvasive and invasive interventions are routinely utilized for children with CMD. Pulmonologists, critical care specialists, and respiratory therapists with pediatric training and experience with neuromuscular disorders are most likely to offer treatment options that optimize respiratory outcomes and minimize infection risks and complications.

\section{Recommendations.}

1. Physicians should counsel families of patients with CMD that respiratory insufficiency and associated problems may be inconspicuous at the outset (Level B).

2. Physicians should monitor pulmonary function tests such as spirometry and oxygen saturation in the awake and sleep states of patients with CMD, with monitoring levels individualized on the basis of the child's clinical status (Level B).

3. Physicians should refer children with CMD to pulmonary or aerodigestive care teams, when available, that are experienced in managing the interface between oropharyngeal function, gastric reflux and dysmotility, and nutrition and respiratory systems, and can provide anticipatory guidance concerning trajectory, assessment modalities, complications, and potential interventions (Level B).

Complications from dysphagia. Patients with neuromuscular disorders often experience dysphagia (impaired swallowing), with implications for growth and nutrition. ${ }^{\text {e57 }}$ Swallowing dysfunction may manifest as failure to thrive and may also increase the risk of admission to critical care units and mortality. Dysphagia may be diagnosed through standard multidisciplinary evaluations and radiologic studies. Safe and adequate nutrition is necessary for optimal health, and thus the potential benefits of improved nutrition with a gastrostomy must be weighed against the potential risks associated with an invasive procedure.

\section{Recommendations.}

1. Neuromuscular specialists should coordinate with primary care providers to follow nutrition and growth trajectories in patients with CMD (Level B).

2. For patients with CMD, physicians should order multidisciplinary evaluations with swallow therapists, gastroenterologists, and radiologists if there is evidence of failure to thrive or respiratory symptoms (or both) (Level B).

3. For patients with $\mathrm{CMD}$, a multidisciplinary care team, taking into account medical and family 
considerations, should recommend gastrostomy placement with or without fundoplication in the appropriate circumstances (Level B).

Cardiac complications. Patients with CMD experience both functional and structural cardiac complications, but the frequency of these for many of the subtypes is unknown. ${ }^{\text {e58-e64 }} \mathrm{On}$ the basis of more extensive experience with cardiac complications in Duchenne MD and Becker MD, cardiac involvement may be subclinical and evident only on echocardiography or ECG (or both) in the earlier stages; such involvement may be amenable to pharmacologic therapy. ${ }^{\mathrm{e} 5}-\mathrm{e} 69$

Recommendation.

1. Physicians should refer children with CMD, regardless of subtype, for a baseline cardiac evaluation. The intervals of further evaluations should depend on the results of the baseline evaluation and the subtype-specific diagnosis (Level B).

Periprocedural complications. Patients with neuromuscular diseases are at increased risk of periprocedural complications, including airway problems, suboptimal pain control, pulmonary complications, prolonged recovery times, and complications of bed rest and deconditioning. ${ }^{\mathrm{e}}{ }^{45, \mathrm{e} 70-\mathrm{e} 72}$

\section{Recommendations.}

1. Before any surgical interventions and general anesthesia in the setting of CMD, physicians should discuss the potential increased risk of complications with patients' families, because these factors may affect decision-making regarding consent to certain elective procedures (Level B).

2. When children with CMD undergo procedures involving sedation or general anesthesia, physicians should monitor longer than usual in the immediate postoperative period to diagnose and treat respiratory, nutritional, mobility, and gastrointestinal mobility complications (Level B).

Musculoskeletal complications. Patients with CMD are at increased risk of musculoskeletal complications, including skeletal deformities and contractures. Rangeof-motion exercises are straightforward interventions that generally do not involve significant risk, but the efficacy of such exercises has not been established. Data on the efficacy of bracing are also lacking for children with CMD. It is generally accepted that orthopedic surgical interventions such as heel cordlengthening procedures relieve tendon contractures at least in the short term; however, the long-term efficacy is unclear. Neuromuscular blocking agents (e.g., botulinum toxin) can cause prolonged worsening of weakness in patients with neuromuscular diseases. ${ }^{\mathrm{e} 73-\mathrm{e} 76}$
1. Physicians should refer to allied health professionals, including physical, occupational, and speech therapists; seating and mobility specialists; rehabilitation specialists; and orthopedic surgeons, to help maximize function and potentially slow the progression of musculoskeletal complications in children with CMD (Level B).

2. Physicians may recommend range-of-motion exercises, orthotic devices, heel cord-lengthening procedures, or a combination of these interventions for children with CMD in certain circumstances (Level B).

3. Physicians might avoid using neuromuscular blocking agents (e.g., botulinum toxin) in patients with CMD, unless the contractures are determined to cause significantly greater impairment than would any potential worsening of weakness in the targeted muscle groups (Level C).

Educational adjustments. Before school age, children at risk of developmental delays are eligible for early intervention services as federally mandated. The Individuals with Disabilities Education Improvement Act of 2004 guarantees children with disabilities a free and appropriate public education. ${ }^{\mathrm{e} 77}$

\section{Recommendation.}

1. Physicians should refer children with CMD to special education advocates, developmental specialists, and education specialists when appropriate for individual circumstances (Level B).

\section{RECOMMENDATIONS FOR FUTURE RESEARCH}

Despite the advances in genetic knowledge of the CMDs, novel CMD genes remain to be discovered. Gaps in knowledge remain in the clinical courses of, complications associated with, and optimal treatment regimens for the various CMD subtypes. Standardized outcome measures would promote more rigorous research that would help identify complications and optimize treatment in these patients. $^{\text {e78 }}$

The following topics merit further research:

1. Gene discovery in CMD

2. Genotype-phenotype studies in CMDs, especially longitudinal studies

3. Frequency and risk factors for various complications in CMDs

4. The merits of various therapeutic interventions for CMDs

\section{AUTHOR CONTRIBUTIONS}

Peter Kang: study concept and design, acquisition of data, analysis or interpretation of data, drafting/revising the manuscript, critical revision 
of the manuscript for important intellectual content, study supervision. Leslie Morrison: study concept and design, acquisition of data, analysis or interpretation of data, drafting/revising the manuscript, critical revision of the manuscript for important intellectual content. Susan Iannaccone: study concept and design, acquisition of data, analysis or interpretation of data, drafting/revising the manuscript, critical revision of the manuscript for important intellectual content. Robert Graham: study concept and design, acquisition of data, analysis or interpretation of data, drafting/revising the manuscript, critical revision of the manuscript for important intellectual content. Carsten Bönnemann: study concept and design, acquisition of data, analysis or interpretation of data, drafting/revising the manuscript, critical revision of the manuscript for important intellectual content. Anne Rutkowski: study concept and design, acquisition of data, analysis or interpretation of data, drafting/revising the manuscript, critical revision of the manuscript for important intellectual content. Joseph Hornyak: study concept and design, acquisition of data, analysis or interpretation of data, drafting/revising the manuscript, critical revision of the manuscript for important intellectual content. Ching Wang: study concept and design, acquisition of data, analysis or interpretation of data, drafting/revising the manuscript, critical revision of the manuscript for important intellectual content. Kathryn North: study concept and design, acquisition of data, analysis or interpretation of data. Maryam Oskoui: analysis or interpretation of data. Thomas Getchius: study supervision. Julie Cox: drafting/revising the manuscript. Erin Hagen: study supervision. Gary Gronseth: study concept and design, acquisition of data, analysis or interpretation of data, drafting/revising the manuscript, critical revision of the manuscript for important intellectual content, study supervision. Robert Griggs: study concept and design, critical revision of the manuscript for important intellectual content.

\section{STUDY FUNDING}

Funding for this publication was made possible (in part) by grant DD101012 from the Centers for Disease Control and Prevention. The findings and conclusions in this report are those of the authors and do not necessarily represent the official position of the Centers for Disease Control and Prevention. The remaining funding was provided by the American Academy of Neurology.

\section{DISCLOSURE}

P. Kang has received funding for travel from the American Academy of Neurology (AAN), the American Academy of Pediatrics (AAP), and Sarepta Therapeutics; has received consulting fees from Third Rock Ventures, Sarepta Therapeutics, and C1 Consulting for work unrelated to continuing medical education; has received honoraria for continuing medical education lectures from the AAN, AAP, American College of Medical Genetics, and HealthmattersCME; and has received research support from the National Institute of Neurological Disorders and Stroke (NINDS) of the NIH and the Muscular Dystrophy Association (MDA). L. Morrison has received funding for travel from the AAN; currently receives funding from the NINDS/NIH and the University of New Mexico (UNM) Myotonic Dystrophy Foundation; has received support from the UNM La Tierra Sagrada Foundation; and serves as director for the pediatric MDA Clinic at UNM, for which she receives annual support. $S$. Iannaccone has received funding for travel from the AAN, Cure CMD, the GBS/CIDP Foundation, and NINDS/NIH; has received research support from the NINDS/NIH, Isis Pharmaceuticals, PTC Therapeutics Inc., Santhera Pharmaceuticals, and GlaxoSmithKline; and serves as director of the MDA Clinic at Children's Medical Center Dallas (for which she receives annual support) and as medical director for the Dallas MDA Summer Camp. R. Graham has served as a one-time, paid consultant for Hoffmann-La Roche Ltd. for a Pulmonary Advisory Panel on investigations pertaining to spinal muscular atrophy (SMA) C. Bönnemann has served on the scientific advisory board of Cure CMD and CMD-IR, without any compensation; has received funding for travel from BioMarin (for scientific advice, no personal compensation), Novartis (no personal compensation), and the Third Rock Ventures (no personal compensation); has served as editor-in-chief of the Journal of Neuromuscular Disorders; sees patients with congenital muscular dystrophy (CMD) and performs muscle ultrasound on patients with CMD; has received intramural funds from the NINDS/NIH and
National Human Genome Research Institute of the NIH; and has received a research grant from MDA, PI. A. Rutkowski has received funding for clinical research from Kaiser Southern California Permanente Medical Group. J. Hornyak has received funding for travel from the AAN. C. Wang reports no disclosures relevant to the manuscript. K. North has received funding to attend a CMD workshop hosted by Cure CMD; has received clinical trials funding from PTC Therapeutics and GSK Prosensa; and has received funding from the Australian National Health and Medical Research Council (for research into congenital myopathies, dysferlin-related muscular dystrophy, and the effect of $\alpha$-actinin-3 deficiency on skeletal muscle performance), from the Australia Research Council (for research into $\alpha$-actinin), and from the US Army Department of Defense (for a clinical trial on lovastatin for the treatment of cognitive deficits in neurofibromatosis type 1). M. Oskoui has received funding for travel from the AAN and Isis Pharmaceuticals; has received fellowship funding from the Spinal Muscular Atrophy Foundation; has received research support from Grifols (Guillain-Barré syndrome), Isis Pharmaceuticals (SMA), and SickKids Foundation (cerebral palsy); and is a member of the Canadian Pediatric Neuromuscular Group and the Canadian Neuromuscular Disease Registry and Network. T. Getchius, J. Cox, E. Hagen, and G. Gronseth report no disclosures relevant to the manuscript. R. Griggs receives support for service on data safety monitoring boards from Novartis, PTC Therapeutics, and ViroMed; consults for Sarepta Pharmaceuticals; consults and has received research support for Marathon Pharmaceuticals and Taro Pharmaceuticals; receives royalties from Elsevier for Cecil Textbook of Medicine and Cecil Essentials of Medicine, and from Oxford University Press for Evaluation and Treatment of Myopathies, Second Edition; receives a stipend from the AAN for editorial work; has received grants from the NINDS/NIH, the MDA, and Parent Project for Muscular Dystrophy; and chairs the Executive Committee of the Muscle Study Group, which receives support from numerous pharmaceutical companies. Go to Neurology.org for full disclosures.

\section{DISCLAIMER}

Clinical practice guidelines, practice advisories, systematic reviews, and other guidance published by the American Academy of Neurology and its affiliates are assessments of current scientific and clinical information provided as an educational service. The information: (1) should not be considered inclusive of all proper treatments, methods of care, or as a statement of the standard of care; (2) is not continually updated and may not reflect the most recent evidence (new evidence may emerge between the time information is developed and when it is published or read); (3) addresses only the question(s) specifically identified; (4) does not mandate any particular course of medical care; and (5) is not intended to substitute for the independent professional judgment of the treating provider, as the information does not account for individual variation among patients. In all cases, the selected course of action should be considered by the treating provider in the context of treating the individual patient. Use of the information is voluntary. AAN provides this information on an "as is" basis, and makes no warranty, expressed or implied, regarding the information. AAN specifically disclaims any warranties of merchantability or fitness for a particular use or purpose. AAN assumes no responsibility for any injury or damage to persons or property arising out of or related to any use of this information or for any errors or omissions.

\section{CONFLICT OF INTEREST}

The American Academy of Neurology and American Association of Neuromuscular \& Electrodiagnostic Medicine are committed to producing independent, critical, and truthful clinical practice guidelines (CPGs). Significant efforts are made to minimize the potential for conflicts of interest to influence the recommendations of this CPG. To the extent possible, the AAN and AANEM keep separate those who have a financial stake in the success or failure of the products appraised in the CPGs and the developers of the guidelines. Conflict of interest forms were obtained from all authors and reviewed by an oversight committee prior to project initiation. AAN and AANEM limit the participation of authors with substantial conflicts of interest. The AAN and AANEM forbid commercial participation in, or funding of, guideline projects. Drafts of the guideline have been reviewed 
by at least 3 AAN committees, at least one AANEM committee, a network of neurologists, Neurology peer reviewers, and representatives from related fields. The AAN Guideline Author Conflict of Interest Policy can be viewed at www.aan.com. For complete information on this process, access the 2004 AAN process manual. ${ }^{1}$

Received July 11, 2014. Accepted in final form December 1, 2014.

\section{REFERENCES}

1. American Academy of Neurology. Clinical Practice Guidelines Process Manual, 2004 ed. St. Paul, MN: The American Academy of Neurology; 2004. Available at: https://www. aan.com/Guidelines/Home/Development. Accessed February 12, 2012. Published 2004

2. American Academy of Neurology. Clinical Practice Guidelines Process Manual, 2011 ed. St. Paul, MN: The American Academy of Neurology; 2011. Available at: https://www. aan.com/Guidelines/Home/Development. Accessed February 12, 2012. Published August 2011.

3. Floriach-Robert M, Cabello A, Simon De Las Heras R, Mateos Beato F. Neonatal hypotonia of muscular origin: analysis of 50 cases [in Spanish]. Neurologia 2001;16:245-253.

4. Mostacciuolo ML, Miorin M, Martinello F, Angelini C, Perini P, Trevisan CP. Genetic epidemiology of congenital muscular dystrophy in a sample from north-east Italy. Hum Genet 1996;97:277-279.

5. Darin N, Tulinius M. Neuromuscular disorders in childhood: a descriptive epidemiological study from western Sweden. Neuromuscul Disord 2000;10:1-9.

6. Bönnemann CG, Wang CH, Quijano-Roy S, et al. Diagnostic approach to the congenital muscular dystrophies. Neuromuscul Disord 2014;24:289-311.

7. Bönnemann CG. The collagen VI-related myopathies: muscle meets its matrix. Nat Rev Neurol 2011;7:379-390.

8. Bönnemann CG. The collagen VI-related myopathies Ullrich congenital muscular dystrophy and Bethlem myopathy. Handb Clin Neurol 2011;101:81-96.

9. Fukuyama Y, Osawa M, Suzuki H. Congenital progressive muscular dystrophy of the Fukuyama type: clinical, genetic and pathological considerations. Brain Dev 1981;3:1-29.

10. Manzini MC, Tambunan DE, Hill RS, et al. Exome sequencing and functional validation in zebrafish identify GTDC2 mutations as a cause of Walker-Warburg syndrome. Am J Hum Genet 2012;91:541-547.

11. Vuillaumier-Barrot S, Bouchet-Séraphin C, Chelbi M, et al. Identification of mutations in TMEM5 and ISPD as a cause of severe cobblestone lissencephaly. Am J Hum Genet 2012;91:1135-1143.

12. Stevens E, Carss KJ, Cirak S, et al. Mutations in B3GALNT2 cause congenital muscular dystrophy and hypoglycosylation of $\alpha$-dystroglycan. Am J Hum Genet 2013;92:354-365.

13. Jae LT, Raaben M, Riemersma M, et al. Deciphering the glycosylome of dystroglycanopathies using haploid screens for lassa virus entry. Science 2013;340:479-483.

14. Buysse K, Riemersma M, Powell G, et al. Missense mutations in $\beta-1,3-\mathrm{N}$-acetylglucosaminyltransferase 1 (B3GNT1) cause Walker-Warburg syndrome. Hum Mol Genet 2013; 22:1746-1754.

15. Carss KJ, Stevens E, Foley AR, et al. Mutations in GDPmannose pyrophosphorylase B cause congenital and limbgirdle muscular dystrophies associated with hypoglycosylation of $\alpha$-dystroglycan. Am J Hum Genet 2013;93:29-41.
16. Hara Y, Balci-Hayta B, Yoshida-Moriguchi T, et al. A dystroglycan mutation associated with limb-girdle muscular dystrophy. N Engl J Med 2011;364:939-946.

17. Kato R, Kawamura J, Sugawara H, Niikawa N, Matsumoto N. A rapid diagnostic method for a retrotransposal insertional mutation into the FCMD gene in Japanese patients with Fukuyama congenital muscular dystrophy. Am J Med Genet A 2004;127A:54-57.

18. Chang W, Winder TL, LeDuc CA, et al. Founder Fukutin mutation causes Walker-Warburg syndrome in four Ashkenazi Jewish families. Prenat Diagn 2009;29:560-569.

19. Balci B, Uyanik G, Dincer P, et al. An autosomal recessive limb girdle muscular dystrophy (LGMD2) with mild mental retardation is allelic to Walker-Warburg syndrome (WWS) caused by a mutation in the POMT1 gene. Neuromuscul Disord 2005;15:271-275.

20. Helbling-Leclerc A, Zhang X, Topaloglu H, et al. Mutations in the laminin alpha 2-chain gene (LAMA2) cause merosin-deficient congenital muscular dystrophy. Nat Genet 1995;11:216-218.

21. Chae JH, Lee JS, Hwang H, et al. Merosin-deficient congenital muscular dystrophy in Korea. Brain Dev 2009;31:341-346.

22. Lim BC, Ki CS, Kim JW, et al. Fukutin mutations in congenital muscular dystrophies with defective glycosylation of dystroglycan in Korea. Neuromuscul Disord 2010; 20:524-530.

23. Camacho Vanegas O, Bertini E, Zhang RZ, et al. Ullrich scleroatonic muscular dystrophy is caused by recessive mutations in collagen type VI. Proc Natl Acad Sci USA 2001; 98:7516-7521.

24. Aparicio Meix JM, Pascual-Castroviejo I. Ullrich syndrome: a hypotonic disorder of early infancy, difficult to define as an entity. An Esp Pediatr 1980;13:979-984.

25. Herrmann R, Straub V, Meyer K, Kahn T, Wagner M, Voit T. Congenital muscular dystrophy with laminin alpha 2 chain deficiency: identification of a new intermediate phenotype and correlation of clinical findings to muscle immunohistochemistry. Eur J Pediatr 1996;155:968-976.

26. Godfrey C, Clement E, Mein R, et al. Refining genotype phenotype correlations in muscular dystrophies with defective glycosylation of dystroglycan. Brain 2007;130: 2725-2735.

27. Diesen C, Saarinen A, Pihko H, et al. POMGnT1 mutation and phenotypic spectrum in muscle-eye-brain disease. J Med Genet 2004;41:e115.

28. Auranen M, Rapola J, Pihko H, et al. Muscle membraneskeleton protein changes and histopathological characterization of muscle-eye-brain disease. Neuromuscul Disord 2000;10:16-23.

29. Cotarelo RP, Fano O, Raducu M, et al. A double homozygous mutation in the POMT1 gene involving exon skipping gives rise to Walker-Warburg syndrome in two Spanish Gypsy families. Clin Genet 2009;76:108-112.

30. Menezes MP, Waddell LB, Evesson FJ, et al. Importance and challenge of making an early diagnosis in LMNA-related muscular dystrophy. Neurology 2012;78:1258-1263.

31. Lamer S, Carlier RY, Pinard JM, et al. Congenital muscular dystrophy: use of brain MR imaging findings to predict merosin deficiency. Radiology 1998;206:811-816.

32. Aida N, Yagishita A, Takada K, Katsumata Y. Cerebellar MR in Fukuyama congenital muscular dystrophy: polymicrogyria with cystic lesions. AJNR Am J Neuroradiol 1994;15:1755-1759. 
33. Bindu PS, Gayathri N, Bharath RD, Mahadevan A, Sinha S, Taly AB. Pattern recognition on brain magnetic resonance imaging in alpha dystroglycanopathies. Neurol India 2010;58:460-465.

34. Brockmann K, Becker P, Schreiber G, Neubert K, Brunner E, Bönnemann C. Sensitivity and specificity of qualitative muscle ultrasound in assessment of suspected neuromuscular disease in childhood. Neuromuscul Disord 2007;17:517-523.

35. Aydinli N, Baslo B, Caliskan M, Ertas M, Ozmen M. Muscle ultrasonography and electromyography correlation for evaluation of floppy infants. Brain Dev 2003;25:22-24.

36. Mercuri E, Clements E, Offiah A, et al. Muscle magnetic resonance imaging involvement in muscular dystrophies with rigidity of the spine. Ann Neurol 2010;67: 201-208.
37. Deconinck N, Dion E, Ben Yaou R, et al. Differentiating Emery-Dreifuss muscular dystrophy and collagen VI-related myopathies using a specific CT scanner pattern. Neuromuscul Disord 2010;20:517-523.

38. Hayashi YK, Koga R, Tsukahara T, et al. Deficiency of laminin alpha 2-chain mRNA in muscle in a patient with merosin-negative congenital muscular dystrophy. Muscle Nerve 1995;18:1027-1030.

39. Ferreira LG, Marie SK, Liu EC, et al. Dystrophin-glycoproteins associated in congenital muscular dystrophy: immunohistochemical analysis of 59 Brazilian cases. Arq Neuropsiquiatr 2005;63:791-800.

40. Geranmayeh F, Clement E, Feng LH, et al. Genotypephenotype correlation in a large population of muscular dystrophy patients with LAMA2 mutations. Neuromuscul Disord 2010;20:241-250. 


\section{Neurology}

Evidence-based guideline summary: Evaluation, diagnosis, and management of congenital muscular dystrophy: Report of the Guideline Development Subcommittee of the American Academy of Neurology and the Practice Issues Review Panel of the American Association of Neuromuscular \& Electrodiagnostic Medicine Peter B. Kang, Leslie Morrison, Susan T. Iannaccone, et al. Neurology 2015;84;1369-1378

DOI 10.1212/WNL.0000000000001416

This information is current as of March 30, 2015

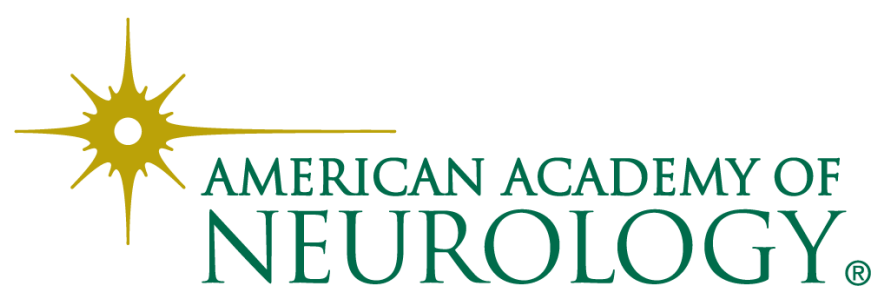




\section{Updated Information \& Services}

\section{Supplementary Material}

References

Citations

Subspecialty Collections

Permissions \& Licensing

\section{Reprints}

including high resolution figures, can be found at: http://n.neurology.org/content/84/13/1369.full

Supplementary material can be found at: http://n.neurology.org/content/suppl/2015/03/28/WNL.0000000000001 416.DC1

This article cites 38 articles, 5 of which you can access for free at: http://n.neurology.org/content/84/13/1369.full\#ref-list-1

This article has been cited by 7 HighWire-hosted articles: http://n.neurology.org/content/84/13/1369.full\#\#otherarticles

This article, along with others on similar topics, appears in the following collection(s):

All Genetics

http://n.neurology.org/cgi/collection/all_genetics

All Imaging

http://n.neurology.org/cgi/collection/all_imaging

All Pediatric

http://n.neurology.org/cgi/collection/all_pediatric

\section{All Rehabilitation}

http://n.neurology.org/cgi/collection/all_rehabilitation Muscle disease

http://n.neurology.org/cgi/collection/muscle_disease

Information about reproducing this article in parts (figures,tables) or in its entirety can be found online at:

http://www.neurology.org/about/about_the_journal\#permissions

Information about ordering reprints can be found online:

http://n.neurology.org/subscribers/advertise

Neurology ${ }^{\circledR}$ is the official journal of the American Academy of Neurology. Published continuously since 1951, it is now a weekly with 48 issues per year. Copyright @ 2015 American Academy of Neurology. All rights reserved. Print ISSN: 0028-3878. Online ISSN: 1526-632X.

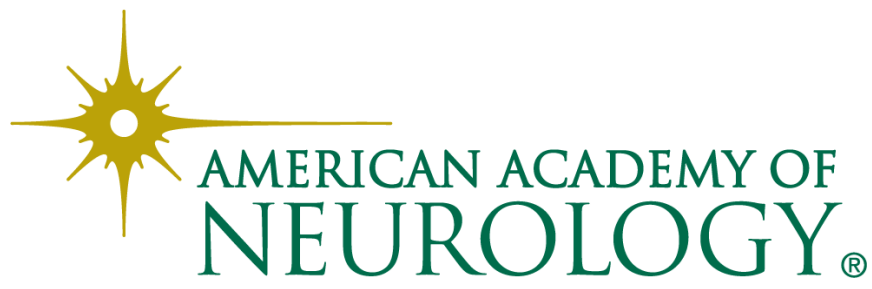

